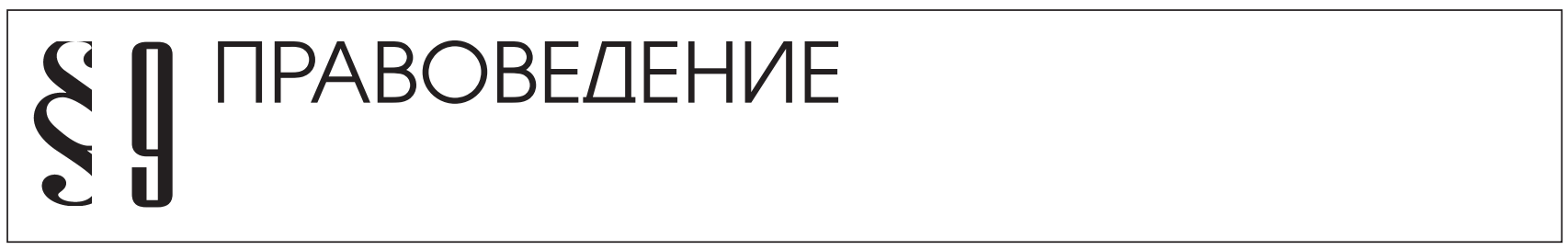

Трубинова Е.И.

\title{
МЕСТО АКТОВ НЕДОБРОСОВЕСТНОЙ КОНКУРЕНЦИИ В СИСТЕМЕ ЮРИДИЧЕСКИХ ФАКТОВ РОССИЙСКОГО ГРАЖДАНСКОГО ПРАВА
}

\begin{abstract}
Аннотация: Одним из наиболее рельефных проявлений такого феномена современного права как конвергенция систем частного и публичного права является конструкция недобросовестной конкуренции, теоретическое осмысление которой возможно исключительно при установлении еёместа в системе юридических фактов гражданского права. Из предлагаемых в науке признаков соответствующих актов и дефинищий недобросовестной конкурениии следует, что понимание недобросовестной конкуренции как юридического факта не является однородным и предполагает несколько групп суждений: 1) недобросовестная конкурениия-злоупотребление субъективным правом; 2) недобросовестная конкурениия суть правонарушение; 3) недобросовестная конкуренция есть проявление юридической ответственности. Недобросовестные конкурентные акты как юридические факты гражданского права выступают разновидностью недозволенных действий, в частности, правонарушений, в ряду которых особое место занимает конструкиия злоупотребления хозяйствующим субъектом своим правом. Установление места актов недобросовестной конкуренции в системе юридических фактов гражданского права имеет существенную практическую значимость, поскольку позволяет определить, подлежат ли применению нормы права общерегулятивного характера к регламентации рассматриваемой конструкции, а также определить состав таких норм. Изложенное в статье позволяет определить место актов недобросовестной конкуренции в системе юридических фактов гражданского права как разновидности недозволенных действий, в частности, правонарушений, в ряду которых особое место занимает конструкиия злоупотребления хозяйствующим субъектом своим правом.

Abstract: The phenomenon of convergence of private and public law systems is quite graphically manifested in the construction of unfair competition, and its theoretical cognition is possible only once its place within the system of legal facts of civil law is established. It follows from the scientifically provided elements of relevant acts and definitions of unfair competition that understanding of unfair competition as a legal fact is non-uniform, and it provides for a number of statements: 1) unfair competition is abuse of a subjective right; 2) unfair competition is an offence; 3) unfair competition is a manifestation of legal liability. Unfair competition acts as legal facts of civil law serve as a type of non-permitted acts, namely, offences, and the construction of abuse of right by an economic subject holds a special place within this structure. Establishing the place of acts of unfair competition within the system of legal facts of civil law is of significant practical importance, since it allows to establish whether the general regulatory norms should apply to this construction, and to define the contents of such norms. The materials provided in this article allow to establish the place of acts of unfair competition within the system of legal cats of civil law as a type of non-permitted activities, namely, offences, especially for the abuse of right by an economic subject.
\end{abstract}

Ключевые слова: Недобросовестная конкуренция, правовые акты, правовое регулирование, потребители, юридическая ответственность, хозяйствующие субъекты, правонарушение, злоупотребление правом, субъективное право, юридический факт.

Keywords: Unfair competition, legal acts, legal regulation, consumers, legal liability, economic subjects, offence, abuse of right, subjective right, legal fact.

овременный этап общественного и государственного развития характеризуется расширением правового пространства, обусловленном как субъективными факторами - стремлением государств с помощью юридических средств исчерпывающим образом воздействовать на экономические и социальные процессы общества, в том числе и на конкурентные акты, так и объектив- 
ными условиями - неспособностью экономических и социальных процессов к абсолютному саморегулированию вне правовой регламентации. Правовое регулирование конструкции недобросовестной конкуренции обусловлено природой конкуренции как процесса соперничества экономических агентов в рамках одной системы за ограниченное количество благ, что означает невозможность существования экономической системы вне стороннего воздействия.

Вместе с тем эффективное недопущение недобросовестной конкуренции является возможным исключительно при формулировании теоретических основ недобросовестной конкуренции - установлении её места в системе юридических фактов гражданского права. Необходимость рассмотрения акта недобросовестной конкуренции как юридического факта определена особой ролью последнего как фактического обстоятельства, которое в силу норм права влечёт наступление юридических последствий и приводит абстрактную норму в действие, что в совокупности с особенностями модели правовой регламентации недобросовестной конкуренции - формулирование общей нормы-дефиниции и открытого перечня её актов - требует уяснения сущности недобросовестной конкуренции как юридического факта.

Определение места недобросовестной конкуренции в системе юридических фактов не представляется возможным в отсутствие ретроспективного обзора теорий, объясняющих её сущность: хронологически первой является возникшая в XIX веке теория генерального деликта, согласно которой недобросовестная конкуренция есть акт злоупотребления правом на конкуренцию. Нормативным основанием теории генерального деликта является ст. 1382 Гражданского кодекса Франции, в соответствии с которой «любое действие человека, причиняющее другому вред, обязывает лицо, виновное в его причинении, этот вред возместить».

Считаем теорию генерального деликта неточной в своём основании, поскольку злоупотребление правом возможно только при условии существования соответствующего права и осуществлении волевых, злонамеренных, недобросовестных действий, противоречащих целевому назначению права. Отличие недобросовестной конкуренции от злоупотребления правом состоит в том, что акт недобросовестной конкуренции представляет собой неоднородное по содержанию нормативное образование, аккумулирующее как действия по злоупотреблению правами на конкуренцию и на объекты гражданских прав, в частности, на средства индивидуализации, так и деликты, ответственность за совершение которых установлена не только в сфере гражданского, но и административного и уголовного права.

В первой половине XX века под влиянием французской судебной практики О. Майер разработал теорию пользования силами в процессе соперничества, которая рассматривала недобросовестную конкуренцию как явление, возникающее при использовании неуправомоченным субъектом сил другого субъекта. Теория пользования силами в процессе соперничества недостаточно точно характеризует явление недобросовестной конкуренции, поскольку акты недобросовестной конкуренции не ограничиваются использованием сил добросовестного конкурента в различных формах, но включают в себя и действия, приводящие к внутренней дезорганизации деятельности предприятия коммерсанта, а также действия по общей дезорганизации рынка.

В середине XX века широкое распространение получила теория коммерческой собственности, которая определяет недобросовестную конкуренцию как посягательство на право собственности добросовестного конкурента. Данная теория признаёт право собственности коммерсантов на нематериальные объекты, а поскольку право собственности является абсолютным правом, то на него недопустимы посягательства недобросовестных конкурентов. Теория коммерческой собственности несёт в себе ошибку, поскольку в силу нематериального характера названных объектов на них может быть установлено не право собственности, но исключительное право, а на ряд объектов - только личные неимущественные права.

Иное понимание недобросовестной конкуренции возникло в конце XIX - начале XX вв. и было оформлено И. Котлером и А. Гирке в теорию личных прав, которая базируется на том, что недобросовестная конкуренция признаётся посягательством на субъективные права участников конкурентной борьбы. Под личными правами предпринимателей эти авторы понимают права на индивидуальность предприятия, имя, честь, репутацию, достоинство лица, тайну частной жизни. Указанная теория экстраполирует концепцию субъективных прав из сферы гражданского в среду торгового права, которое обеспечивает охрану и защиту тех же «личных прав», но в сфере коммерческого оборота.

Теория личных прав допускает одностороннее толкование явления недобросовестной конкуренции. Так, акты недобросовестной конкуренции направлены не только на субъективные права добросовестных конкурентов, но и на потребителей. Как указывает Г.Ф. Шершеневич, «конкуренция прежде всего проис- 


\section{Право и политика 4 (172) $\bullet 2014$}

ходит на почве качества предлагаемых товаров: каждое предприятие стремится привлечь к себе внимание потребителей действительными или мнимыми преимуществами своих товаров перед товарами соперников» ${ }^{1}$.

Представляется, что основой для определения места недобросовестной конкуренции в системе юридических фактов должна выступить теория личных прав как наиболее точное обоснование её сущности, поскольку данная теория переносит субъективные права из гражданского права в торговое, обеспечивает защиту тех же «личных прав», но в сфере коммерческого оборота, что также подтверждает частноправовой характер регулирования недобросовестной конкуренции в отличие от публично-правовых признаков регламентации монополистической деятельности.

Правомерность постановки вопроса об определении места недобросовестных конкурентных актов в системе юридических фактов именно гражданского права обусловлена как потребностями гражданского оборота, отражающимися в нормативных актах и материалах правоприменительной практики, так и теоретическими основами рассматриваемого явления. Так, конкурентное законодательство основывается, в частности, на нормах Гражданского кодекса Российской Федерации (далее - ГК РФ), подлежащих применению при рассмотрении дел о недобросовестной конкуренции ${ }^{2}$, а само конкурентное законодательство формулирует требования для хозяйствующих субъектов при их вступлении в гражданско-правовые отношения с другими участниками гражданского оборота, устанавливая в том числе запрет на недобросовестную конкуренцию.

Конструкция недобросовестной конкуренции аккумулирует как преимущественно частноправовые черты, так и публично-правовые свойства, которые связаны с введением в состав конструкции недобросовестной конкуренции фигуры потребителя - представителя общественности, чьи права и законные интересы подлежат защите. Наличие публично-правовых характеристик не препятствует включению недобросовестных конкурентных актов в систему юридических фактов гражданского права, поскольку конструкция недобросовестной конкуренции имеет место исключительно в имущественных отношениях, которые носят эквивалентно-возмездный характер и, соответственно, под-

\footnotetext{
${ }^{1}$ Шериеневич Г.Ф. Учебник торгового права (по изданию 1914г.). М.: Фирма «СПАРК», 1994. С.110.

${ }^{2}$ См.: Обзор практики применения арбитражными судами статьи 10 Гражданского кодекса Российской Федерации: Информационное письмо Президиума ВАС РФ от 25.11.2008 № 127 // Вестник ВАС РФ. 2009. № 2. - П. 8.
}

лежат включению в предмет гражданского права. При этом соответствующие отношения выступают основой для гражданско-правового регулирования, в отсутствие которого конкуренция между хозяйствующими субъектами крайне затруднительна, поскольку соответствующий метод регламентации характеризуется наделением субъектов на началах их юридического равенства способностью к правообладанию, диспозитивностью и инициативой, обеспечивает установление правоотношений на основе правовой самостоятельности сторон ${ }^{3}$.

В науке вопрос об определении недобросовестного конкурентного акта как юридического факта самостоятельному рассмотрению не подвергался. Однако, из предлагаемых признаков соответствующих актов и дефиниций недобросовестной конкуренции следует, что понимание недобросовестной конкуренции как юридического факта не является однородным и предполагает две группы суждений.

Сторонники первой точки зрения ограничивают понимание недобросовестной конкуренции исключительно злоупотреблением правом, одной из её форм, выражающейся в противоправном поведении субъекта рыночных отношений, который посредством недозволенных законом или противоречащих обычаям делового оборота форм реализации своего субъективного права создаёт помехи в осуществлении его конкурентами своих предпринимательских прав или наносит ущерб потребителям ${ }^{4}$. Восприятие недобросовестной конкуренции как злоупотребления правом существенным образом ограничивает её содержание.

Конструкция злоупотребления правом требует наличия соответствующего права у субъекта, нарушения прав иных участников гражданского оборота при реализации лицом представленных ему в рамках субъективного права правомочий, а также отсутствия при этом прямого нарушения норм (за исключением отступления от нормы-принципа и нормы-презумпции добросовестности участников гражданских правоотношений). Вместе с тем существующая дефиниция недобросовестной конкуренции предполагает, что к соответствующим актам при наличии иных закреплённых в норме признаков относятся не только противоречащие требованиям добропорядочности, разумности и справедливости действия, но и те проявления, которые противоречат законодательству

\footnotetext{
${ }^{3}$ Яковлев В.Ф. Гражданско-правовой метод регулирования общественных отношений. М.: Статут, 2006. С. 190.

${ }^{4}$ См.: Долгих М.Г. Юридическая природа недобросовестной конкуренции // Законодательство. 2003. № 11. С. 34.
} 
Российской Федерации и обычаям делового оборота, а ст. 14 Федерального закона от 26.07.2006г. № 135-Ф3 «О защите конкуренции» (далее - Закон о защите конкуренции) предусматривает открытый перечень недобросовестных конкурентных актов, осуществление которых запрещено, что не предполагает допустимости использования таких действий при осуществлении лицом субъективного права. Получается, что злоупотреблением правом содержание актов недобросовестной конкуренции не исчерпывается.

Следует отметить, что некоторыми авторами возможность применения конструкции злоупотребления правом к конкурентным отношениям отрицается, поскольку в соответствующих отношениях имеет место не злоупотребление правом, но выход за пределы установленных законом дозволений5. Однако метод правового регулирования связанных с недопущением недобросовестной конкуренции отношений предполагает не дозволительный, но характеризующийся значительной степенью диспозитивности способ воздействия, вследствие чего допустимы любые проявления конкуренции, не отвечающие изложенным в норме-дефиниции недобросовестной конкуренции признакам. Не препятствует применимости конструкции злоупотребления правом к недобросовестным конкурентным действиям и нормативное закрепление общего понятия недобросовестной конкуренции, поскольку последнее в качестве одного из необходимых признаков определяемого явления именует противоречащие требованиям добропорядочности, разумности и справедливости действия, иное толкование приводит к отрицанию возможности злоупотребления правом в правовой системе России, поскольку ГК РФ предусматривает норму-принцип и норму-презумпцию добросовестности.

Какое субъективное право может являться предметом злоупотребления, отвечающего при этом признакам акта недобросовестной конкуренции? Предметом злоупотребления может выступать исключительное право на средства индивидуализации юридического лица, средства индивидуализации продукции, работ или услуг, что следует из норм п. 2 ст. 14 Закона о защите конкуренции, а также иное субъективное право на конкретный объект.

В литературе также встречается суждение, согласно которому в качестве общего предмета злоупотребления правом, содержащего признаки недобросовестной кон-

\footnotetext{
${ }^{5}$ Уруков В.Н. Злоупотребление гражданскими правами // Вестник Юридического института Чувашского государственного университета им. И.Н. Ульянова. 2007. № 1. С. 119.
}

куренции, выступает «право на конкуренцию» ${ }^{6}$, содержание которого определено ч. 1 ст. 34 Конституции РФ, - свободное использование субъектом способностей и имущества для предпринимательской и иной не запрещённой законом экономической деятельности. Для применения конструкции злоупотребления правом к действиям необходимо, чтобы недобросовестный конкурент в качестве основания своих деяний указывал на обладание соответствующим субъективным правом, содержание которого должно носить конкретный характер. Из правоприменительной практики следует, что недобросовестный хозяйствующий субъект в качестве основания притязаний не ссылается на обладание «правом на конкуренцию», но на конкретные субъективные права на объекты7. Однако изложенные обстоятельства не исключают существования у хозяйствующих субъектов права на конкуренцию, которое позволяет конкурентам свободно осуществлять экономическую деятельность, в том числе при использовании субъективных прав на различные объекты.

Более широкое толкование сущности недобросовестной конкуренции встречается в работах приверженцев иной точки зрения, полагающих, что недобросовестная конкуренция суть правонарушение, нарушение правил конкуренции, направленное на приобретение преимуществ в предпринимательской деятельности ${ }^{8}$.

В научной литературе Франции также распространено мнение о квалификации недобросовестной конкуренции не как юридического факта, но собственно гражданской или дисциплинарной ответственности 9 . Рассмотрение недобросовестной конкуренции как вида юридической ответственности не соответствует как основам теории права, так и особенностям её нормативного регулирования. Юридическая ответственность есть следствие недозволенного действия - юридического факта «вне зависимости от того, какие решения компетентных органов власти были приняты или не были

\footnotetext{
${ }^{6}$ Голикова О.В. Недобросовестная конкуренция и злоупотребление правом // Конкурентное право. 2011. № 1. С. 39 - 45.

${ }^{7}$ См.: Постановление ФАС Волго-Вятского округа от 16.06.2008 по делу № A43-2795/2007-38-584 [Электронный ресурс]. Документ опубликован не был. Доступ из справ.-правовой системы «КонсультантПлюс».

${ }^{8}$ См.: Брюховеиякий Н.Н. Недобросовестная конкуренция: основное, что должен знать руководитель // Право и экономика. 2008. № 6. C. 8 - 9 .

${ }^{9}$ См.: Чудинов О.Р. Классификация недобросовестных конкурентных действий правом Франции (по материалам правоприменительной практики судов Франции) // Вестник Пермского национального исследовательского политехнического университета. Культура, история, философия, право. 2012. № 5. С. 52 - 53.
} 
DOI: $10.7256 / 1811-9018.2014 .4 .11452$

При цитировании этой статьи сноска на доі обязательна

\section{Право и политика 4 (172) 2014}

реализованы впоследствии» ${ }^{10}$. Собственно конструкция недобросовестной конкуренции не является видом юридической ответственности, но при соответствии акта содержащимся в её норме-дефиниции признакам недобросовестный конкурент привлекается к гражданско-правовой, административной ответственности, а также может быть привлечён к уголовной ответственности. Более того, нормы Закона о защите конкуренции, определяющие недобросовестную конкуренцию и закрепляющие открытый перечень её актов, не включают в свою структуру санкцию, которая является необходимым нормативным основанием привлечения к юридической ответственности.

Возможно ли рассматривать акты недобросовестной конкуренции в системе юридических фактов исключительно в качестве разновидности недозволенных юридических действий? Как справедливо замечает М.А. Рожкова, не каждое недозволенное действие будет правонарушением, а только то, которое повлекло за собой причинение ущерба частному лицу и иное нарушение прав другого лица, при этом под недозволенными действиями необходимо понимать проступки и правонарушения, которые нарушают гражданский оборот, вызывают потребность его восстановления ${ }^{11}$. Безусловно, недобросовестная конкуренция как юридический факт относима к недозволенным действиям, поскольку реализация таких актов зависит от воли соответствующих хозяйствующих субъектов, нарушает субъективные права и интересы иных лиц: конкурентов, контрагентов, потребителей и общества в целом, - а также не соответствует требованиям норм объективного права.

При этом недобросовестная конкуренция аккумулирует как действия по злоупотреблению правом, так и нарушения норм объективного права. При этом ограничение сущности недобросовестной конкуренции исключительно нарушающими нормы объективного права действиями не представляется возможным, поскольку попытки предусмотреть весь спектр возможных актов недобросовестных конкуренции нарушают эффективность её нормативного регулирования, при котором необходимо соблюдение границ правового и правосвободного пространств. Сферой нормативного регулирования конкуренции и недопущения недобросовестной конкуренции является правовое простран-

\footnotetext{
${ }^{10}$ Коробов А.Е., Хохлов Е.Б. Правонарушение как основание юридической ответственности // Известия высших учебных заведений. Правоведение. 2009. № 3. С. 65.

${ }_{11}$ Рожкова М.А. Юридические факты в гражданском праве // Хозяйство и право (Приложение). 2006. № 7. 80с.
}

ство, а правосвободное пространство не предполагает абсолютного произвола экономических агентов, но допускает ненормативное регулирование экологоприродными, культурно-историческими (этическими, эстетическими, религиозными) факторами. Пределы нормативного регулирования явления конкуренции, в частности, недопущения недобросовестной конкуренции, определяются природой правового пространства: у экономических агентов объективно должна существовать возможность избрания конкурентной стратегии и модели хозяйственной деятельности.

Справедливо ли ограничение недобросовестных конкурентных актов исключительно правонарушениями? Разрешение данного вопроса зависит от определения соответствующего признакам недобросовестной конкуренции злоупотребления правом как правонарушения либо как самостоятельного юридического факта. Рядом авторов отмечается, что злоупотребление правом правонарушением не является, поскольку это есть особый тип правового поведения, выражающийся в недостойной форме осуществления права ${ }^{12}$. Злоупотребление правом действительно предполагает такую форму реализации лицом предоставленных ему правомочий, при которой имеет место нарушение субъективных прав других лиц, а, как справедливо указывается в литературе, «в гражданском праве существуют субъективные права, обосновать нарушение и необходимость защиты которых только через нарушение конкретных норм невозможно» ${ }^{13}$. Получается, что следует разделить преобладающую точку зрения, в соответствии с которой злоупотребление правом есть особый тип гражданского правонарушения ${ }^{14}$, иное суждение лишает конструкцию рассматриваемую конструкцию необходимой специфики, правомерного злоупотребления правом существовать не может, иначе такие действия злоупотреблением правом не являются.

Наличие специального правового регулирования недобросовестной конкуренции, в том числе и в сфере прав на средства индивидуализации, не исключает применения к таким действиям общих по характеру

\footnotetext{
${ }^{12}$ См.: Филиппова T.А. Осуществление субъективных гражданских прав и злоупотребление ими // Цивилистические заметки. Субъективные права: Осуществление и защита. Сборник научных статей. Барнаул: Издательство Алтайского государственного университета, 2004. С. 8.

${ }^{13}$ Шевченко А.С., Шевченко Г.Н. Деликтные обязательства в российском гражданском праве. М.: Статут, 2013. С. 37.

${ }^{14}$ См.: Кация Т.В. Злоупотребление субъективным гражданским правом // Закон. 2009. № 3. С. 206 - 207.
} 
норм, что находит отражение и в материалах правоприменительной практики ${ }^{15}$. Предлагаемое в науке $\mathrm{e}^{16}$ исключение конструкции недобросовестной конкуренции из сферы нормативной регламентации содержащихся в ГК РФ нормы-принципа и нормы-презумпции добросовестности влечёт существенные правовые последствия, а именно лишает хозяйствующих субъектов-конкурентов и потребителей возможности ссылаться на злоупотребление недобросовестным конкурентом правом, чтобы при рассмотрении спора последнему было отказано в защите.

Отказ в защите права, при осуществлении которого субъект злоупотребляет предусмотренными ним правомочиями, не исключает возможности применения добросовестными конкурентами и потребителями иного способа защиты - требования возмещения причинённых злоупотреблением убытков. Однако применение рассматриваемых норм возможно только в случае, когда причинение убытков другим хозяйствующим субъектам-конкурентам и (или) потребителям либо нанесение или возможность нанесения вреда деловой репутации хозяйствующих субъектовконкурентов обусловлены злоупотреблением лицом своим субъективным правом и при условии, что такой субъект в качестве основания своих действий ссылается на обладание таким правом.

Изложенное позволяет определить место актов недобросовестной конкуренции в системе юридических фактов гражданского права как разновидности недозволенных действий, в частности, правонарушений, в ряду которых особое место занимает конструкция злоупотребления хозяйствующим субъектом своим правом.

\section{Библиография:}

1. Шершеневич Г.Ф. Учебник торгового права (по изданию 1914г.). М.: Фирма «СПАРК», 1994. 335с.

2. Обзор практики применения арбитражными судами статьи 10 Гражданского кодекса Российской Федерации: Информационное письмо Президиума ВАС РФ от 25.11.2008 № 127 // Вестник ВАС РФ. 2009. № 2 .

\footnotetext{
15 См.: Постановление Суда по интеллектуальным правам от 11.02.2014 по делу № А60-52709/2011 [Электронный ресурс]. Документ опубликован не был. Доступ из справ.-правовой системы «КонсультантПлюс».

${ }^{16}$ См.: Волков A. Недобросовестная конкуренция и злоупотребления доминирующим положением на рынке как формы злоупотребления правом // Законность. 2009. № 11. С. 34 - 35 .
}

3. Яковлев В.Ф. Гражданско-правовой метод регулирования общественных отношений. М.: Статут, 2006. 240c.

4. Долгих М.Г. Юридическая природа недобросовестной конкуренции // Законодательство. 2003. № 11. C. $31-34$.

5. Уруков В.Н. Злоупотребление гражданскими правами // Вестник Юридического института Чувашского государственного университета им. И.Н. Ульянова. 2007. № 1. С. 116 - 135.

6. Голикова О.В. Недобросовестная конкуренция и злоупотребление правом // Конкурентное право. 2011. № 1. С. $39-45$.

7. Постановление ФАС Волго-Вятского округа от 16.06.2008 по делу № А43-2795/2007-38-584 [Электронный ресурс]. Документ опубликован не был. Доступ из справ.-правовой системы «КонсультантПлюс».

8. Брюховецкий Н.Н. Недобросовестная конкуренция: основное, что должен знать руководитель // Право и экономика. 2008. № 6. С. 8 - 12 .

9. Чудинов О.Р. Классификация недобросовестных конкурентных действий правом Франции (по материалам правоприменительной практики судов Франции) // Вестник Пермского национального исследовательского политехнического университета. Культура, история, философия, право. 2012. № 5. С. $50-67$.

10. Коробов А.Е., Хохлов Е.Б. Правонарушение как основание юридической ответственности // Известия высших учебных заведений. Правоведение. 2009. № 3. С. $62-75$.

11. Рожкова М.А. Юридические факты в гражданском праве // Хозяйство и право (Приложение). 2006. № $7.80 \mathrm{c}$.

12. Филиппова Т.А. Осуществление субъективных гражданских прав и злоупотребление ими // Цивилистические заметки. Субъективные права: Осуществление и защита. Сборник научных статей. Барнаул: Издательство Алтайского государственного университета, 2004. С. 5 - 10.

13. Шевченко А.С., Шевченко Г.Н. Деликтные обязательства в российском гражданском праве. М.: Статут, 2013. 133c.

14. Кация Т.В. Злоупотребление субъективным гражданским правом // Закон. 2009. № 3. С. $200-211$.

15. Постановление Суда по интеллектуальным правам от 11.02.2014 по делу № А60-52709/2011 [Электронный ресурс]. Документ опубликован не был. Доступ из справ.-правовой системы «КонсультантПлюс». 


\section{Право и политика 4 (172) $\bullet 2014$}

16. Волков А. Недобросовестная конкуренция и злоупотребления доминирующим положением на рынке как формы злоупотребления правом // Законность. 2009. № 11. С. $31-35$.

17. А.В. Манойло. Психологические операции в политической и экономической конкуренции. // Национальная безопасность / nota bene. - 2009. - № 3.

18. Г.Ю. Атаян, О.Н. Амвросова. Принципы правовой политики современного государства в сфере экономики // Право и политика. - 2009. - № 8.

19. Павлов С.А.. Антимонопольное законодательство как инструмент развития рыночной экономики в России // Право и политика. - 2013. - № 8. - С. 104 107. DOI: 10.7256/1811-9018.2013.8.1180.

20. Тихонов А.А.. Выбор модели стратегического управления развитием сельскохозяйственных предприятий // Тренды и управление. - 2013. - № 3. - С. 82-90. DOI: 10.7256/23079118.2013.3.9402.

21. Камзин Н.Л.. Предпринимательский риск: необходимость защиты, сущность // Тренды и управление. - 2013. - № 3. - С. 128-134. DOI: 10.7256/23079118.2013.3.6338.

22. О.В. Веретенов. Рынок леса: инвестиционные проекты и их возможные риски // Тренды и управление. - 2013. - № 1. - С. 49-53. DOI: 10.7256/23079118.2013.01.6.

23. Е.В. Бурцева. Основные подходы к совершенствованию методов оценки финансовой устойчивости промышленных предприятий в условиях нестабильности // Тренды и управление. - 2013. - № 1 . - С. 78-89. DOI: 10.7256/2307-9118.2013.01.9

\section{References (transliteration):}

1. Shershenevich G.F. Uchebnik torgovogo prava (po izdaniyu 1914g.). M.: Firma «SPARK», 1994. $335 \mathrm{~s}$.

2. Yakovlev V.F. Grazhdansko-pravovoi metod regulirovaniya obshchestvennykh otnoshenii. M.: Statut, 2006. 240s.

3. Dolgikh M.G. Yuridicheskaya priroda nedobrosovestnoi konkurentsii // Zakonodatel'stvo. 2003. № 11. S. $31-34$.

4. Urukov V.N. Zloupotreblenie grazhdanskimi pravami // Vestnik Yuridicheskogo instituta Chuvashskogo gosudarstvennogo universiteta im. I.N. Ul'yanova. 2007. № 1. S. 116 - 135 .
5. Golikova O.V. Nedobrosovestnaya konkurentsiya i zloupotreblenie pravom // Konkurentnoe pravo. 2011. № 1 . S. $39-45$.

6. Bryukhovetskii N.N. Nedobrosovestnaya konkurentsiya: osnovnoe, chto dolzhen znat' rukovoditel' // Pravo i ekonomika. 2008. № 6. S. 8-12.

7. Chudinov O.R. Klassifikatsiya nedobrosovestnykh konkurentnykh deistvii pravom Frantsii (po materialam pravoprimenitel'noi praktiki sudov Frantsii) // Vestnik Permskogo natsional'nogo issledovatel'skogo politekhnicheskogo universiteta. Kul'tura, istoriya, filosofiya, pravo. 2012. № 5. S. 50 - 67.

8. Korobov A.E., Khokhlov E.B. Pravonarushenie kak osnovanie yuridicheskoi otvetstvennosti // Izvestiya vysshikh uchebnykh zavedenii. Pravovedenie. 2009. № 3. S. $62-75$.

9. Rozhkova M.A. Yuridicheskie fakty v grazhdanskom prave // Khozyaistvo i pravo (Prilozhenie). 2006. № 7. 80s.

10. Filippova T.A. Osushchestvlenie sub'ektivnykh grazhdanskikh prav i zloupotreblenie imi // Tsivilisticheskie zametki. Sub' 'ektivnye prava: Osushchestvlenie i zashchita. Sbornik nauchnykh statei. Barnaul: Izdatel'stvo Altaiskogo gosudarstvennogo universiteta, 2004. S. 5 - 10.

11. Shevchenko A.S., Shevchenko G.N. Deliktnye obyazatel'stva v rossiiskom grazhdanskom prave. M.: Statut, 2013. 133s.

12. Katsiya T.V. Zloupotreblenie sub"ektivnym grazhdanskim pravom // Zakon. 2009. № 3. S. $200-211$.

13. Volkov A. Nedobrosovestnaya konkurentsiya i zloupotrebleniya dominiruyushchim polozheniem na rynke kak formy zloupotrebleniya pravom // Zakonnost'. 2009. № 11. S. 31 - 35.

14. A.V. Manoilo. Psikhologicheskie operatsii v politicheskoi i ekonomicheskoi konkurentsii. // Natsional'naya bezopasnost' / nota bene. - 2009. - № 3.

15. G.Yu. Atayan, O.N. Amvrosova. Printsipy pravovoi politiki sovremennogo gosudarstva v sfere ekonomiki // Pravo i politika. - 2009. - № 8.

16. Pavlov S.A.. Antimonopol'noe zakonodatel'stvo kak instrument razvitiya rynochnoi ekonomiki v Rossii // Pravo i politika. - 2013. - № 8. - S. 104-107. DOI: 10.7256/1811-9018.2013.8.1180.

17. Tikhonov A.A.. Vybor modeli strategicheskogo upravleniya razvitiem sel'skokhozyaistvennykh predpriyatii // Trendy i upravlenie. - 2013. - № 3. - S. 82-90. DOI: 10.7256/2307-9118.2013.3.9402.

18. Kamzin N.L.. Predprinimatel'skii risk: neobkhodimost' zashchity, sushchnost' // Trendy i upravlenie. 
DOI: $10.7256 / 1811-9018.2014 .4 .11452$

При цитировании этой статьи сноска на dоі обязательна

Правоведение

- 2013. - № 3. - S. 128-134. DOI: 10.7256/23079118.2013.3.6338.

19. O.V. Veretenov. Rynok lesa: investitsionnye proekty $\mathrm{i}$ ikh vozmozhnye riski // Trendy i upravlenie. - 2013. - № 1. - S. 49-53. DOI: 10.7256/2307-9118.2013.01.6.
20. E.V. Burtseva. Osnovnye podkhody k sovershenstvovaniyu metodov otsenki finansovoi ustoichivosti promyshlennykh predpriyatii v usloviyakh nestabil'nosti // Trendy i upravlenie. - 2013. - № 1. - S. 78-89. DOI: 10.7256/2307-9118.2013.01.9 